\title{
MANAJEMEN KLINIS CU-SIL DENTURE PADA PASIEN DENGAN SEDIKIT GIGI ASLI YANG TERSISA
}

\author{
Silmi Gusdayuni ${ }^{1}$, Eni Rahmi ${ }^{1}$ \\ ${ }^{\mathbf{1}}$ Fakultas Kedokteran Gigi Universitas Andalas
}

\begin{abstract}
Nowadays one of the prime concern in dentistry is on preservation of remaining natural teeth. Many patients require replacement of missing teeth and associated structures to enhance appearance, improve masticatory efficiency, prevent unwanted movement of teeth (overeruption/drifting), and/ or improve phonetics. Presence of few teeth in oral cavity helps in preserving alveolar ridge integrity, maintain the proprioception, and gives psychological benefit to the patient. This case report presents a case of a 54-years-old female with few remaining teeth, one remaining tooth in maxilla and two remaining teeth in mandible. Patient wants to get her masticatory function and aestethic back with maintain her remaining teeth. $\mathrm{Cu}$-sil denture is one of the simplest removable partial denture that can replace missing teeth where only few teeth remain in oral cavity. A Cu-sil denture is a denture with holes, lined by a gasket, the holes that providing space for remaining natural teeth to emerge into the oral cavity through the denture.
\end{abstract}

Keywords: cu-sil denture; gasket; few remaining teeth; missing teeth

Affiliasi penulis: ${ }^{1}$ Fakultas Kedokteran Gigi Universitas Andalas Korespondensi: eni rahmi, email: eni.rahmi@dent.unand.ac.id

\section{PENDAHULUAN}

Pada saat sekarang ini, kebutuhan terhadap protesa gigi sudah dianggap penting. Salah satu alasan yang dilaporkan pasien adalah anggapan tentang kebutuhan gigi merupakan kebutuhan estetik, yang membuat mereka merasa lebih baik dan lebih percaya diri ketika tersenyum. Gigi geligi membantu mempertahankan oklusi dan hubungannya dengan otototot pengunyahan, mandibula, maksila, dan sendi temporomandibula. ${ }^{1}$ Oleh karena kebutuhan dalam pemeliharaan kesehatan mulut telah meningkat, orangorang yang kehilangan sedikit gigi, juga menyebabkan peningkatan kebutuhan perawatan pada kehilangan gigi sebagian dibandingkan kehilangan gigi seluruhnya. Kebanyakan pasien membutuhkan pengganti gigi yang hilang dan struktur yang terlibat karena ingin meningkatkan penampilan, meningkatkan efisiensi pengunyahan, mencegah pergerakan gigi yang tidak diinginkan (overerupsi atau drifting), dan/ atau meningkatkan fungsi fonetik. ${ }^{2}$

Pilihan perawatan pada rahang yang memiliki sedikit gigi yang tersisa adalah overdentures, immediate denture, dan transitional denture. Transitional dentures terbukti menjadi perawatan yang baik untuk pasien yang tidak ingin melakukan ekstraksi atau prosedur endodontik. $\mathrm{Cu}$-sil denture merupakan salah satu bentuk transitional denture, 
yang dipilih untuk perawatan dalam praktik kedokteran gigi tetapi dapat terbukti mudah dan terjangkau. ${ }^{3}$

$\mathrm{Cu}$-sil denture pada dasarnya merupakan gigi tiruan lengkap dengan lubang yang membuat gigi asli yang tersisa dapat muncul pada gigi tiruan. Lubang tersebut dikelilingi oleh gasket yang terbuat dari silicone rubber yang memeluk leher dari gigi asli, sehingga terbentuk suatu natural suction pada gigi tiruan. Gigi tiruan ini merupakan gigi tiruan sebagian lepasan yang paling sederhana, tetapi membutuhkan alat dan bahan khusus, yang membuat tekniknya sensitif, membutuhkan waktu, dan mahal. $^{3}$

\section{KASUS}

Pasien perempuan berusia 54 tahun datang ke RSGMP Universitas Andalas dengan keluhan banyak gigi yang hilang sehingga pasien ingin dibuatkan gigi tiruan. Gigi pasien hilang dimulai dari gigi belakang bawah sejak sekitar sepuluh tahun yang lalu akibat gigi berlubang kemudian patah-patah. Pasien sulit mengunyah makanan dan merasa kurang percaya diri. Pasien belum pernah memakai gigi tiruan sebelumnya. Pasien pernah memiliki riwayat tensi tinggi sekitar tahun 2014 yang lalu, tetapi setelah itu tidak pernah ada keluhan yang dirasakan pasien dan tidak pernah kontrol ke dokter.
Hasil pemeriksaan klinis menunjukkan pasien memiliki bentuk muka lonjong dan asimetris, profil cembung, pupil dan tragus sama tinggi, hidung simetris, rima oris normal, bibir atas dan bawah normal dan simetris, kelenjar getah bening tidak ada kelainan, sendi rahang kanan tidak ada kelainan, sendi rahang kiri clicking dan tidak nyeri, bukaan mulut deviasi ke kanan, serta tidak terdapat kelainan lainnya.
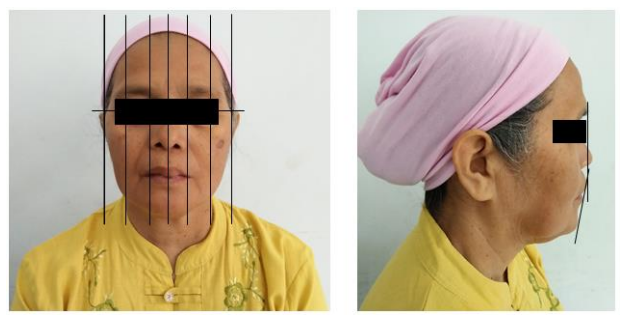

Gambar 1. Foto ekstra oral

Hasil pemeriksaan intra oral menunjukkan kebersihan mulut sedang, ada kalkulus, tidak ada stain, kuantitas dan konsistensi saliva normal, ukuran dan mobilitas lidah normal dengan posisi Wright kelas 1, refleks muntah rendah, dan mukosa mulut tidak ada kelainan. Vestibulum rahang atas dan bawah kanan, anterior, dan kiri dangkal, kecuali pada vestibulum rahang bawah anterior sedang. Tahanan jaringan pada prosesus alveolaris rahang atas dan rahang bawah rendah.

Pada pemeriksaan gigi geligi, gigi yang tersisa adalah gigi 14 dengan karies media di mesial dan karies superfisial di distal serta mobiliti derajat 1 ; gigi 12 dengan karies profunda, gigi 21 dengan 
karies media dan karies superfisial di distal serta mobiliti derajat 1; gigi 34 dengan karies superfisial di mesial; gigi 32, 31, dan 41 dengan keadaan mobiliti derajat 1; gigi 43 dengan karies superfisial di distal; terdapat radiks pada gigi $13,11,22,24,25,26,27,28,33$, dan 42. Pada hasil foto rontgen terlihat adanya pola tulang dengan trabekulasi padat jarang bergantian dengan padat lebih banyak.

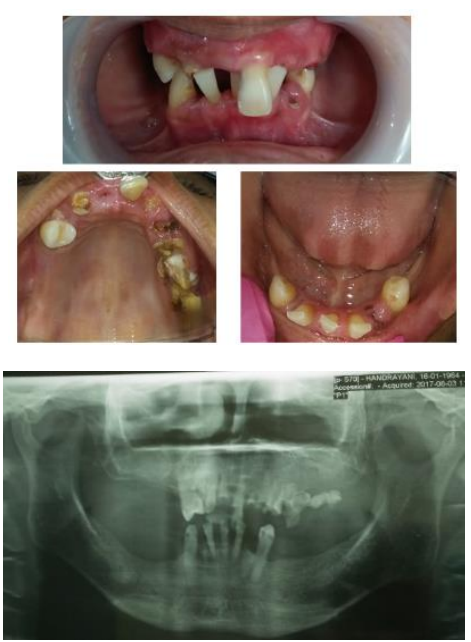

Gambar 2. Gambaran intra oral dan radiografi

Diagnosis pada kasus ini adalah Kennedy kelas I pada rahang atas dan Kennedy kelas I modifikasi 1. Perawatan pada kasus ini adalah gigi tiruan sebagian lepasan akrilik dengan elemen gigi artifisial gigi 17-15 dan 13-27 dengan dukungan mukosa pada rahang atas ditambah dengan gasket pada gigi 14. Pada rahang bawah dilakukan pembuatan gigi tiruan sebagian lepasan akrilik dengan elemen gigi artifisial gigi 37-35, 33-42, dan 44-47 dengan dukungan mukosa ditambah dengan gasket pada gigi 34 dan 43. Perawatan pra prostodontik yang dilakukan meliputi perawatan periodontal berupa scaling dan root planing; perawatan bedah mulut berupa pencabutan gigi 1322, 24-28, dan 33-42, perawatan konservasi berupa restorasi resin komposit pada gigi 14 (klas II), 34 (klas II), dan 43 (klas III).

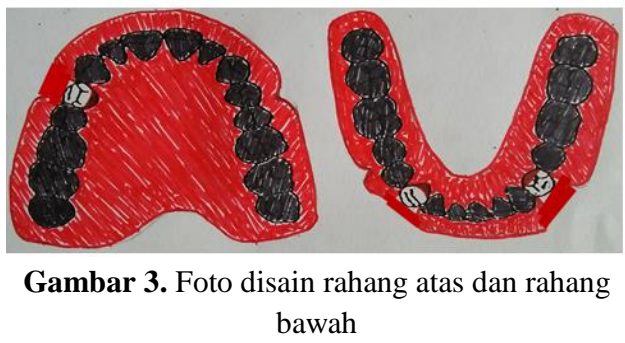

Disain gigi tiruan rahang atas dan rahang bawah memiliki dukungan mukosa dengan perluasan basis sampai tuberositas maksila, palatum durum, dan residual alveolar ridge untuk rahang atas dan perluasan basis sampai retromolar pad dan residual alveolar ridge untuk rahang bawah. Retensi diperoleh dari faktor fisik yang didapat dari tegangan permukaan, adhesi, dan kohesi; faktor fisiologis yang didapat dari anatomi denture bearing area, dukungan muskular, dan gaya kunyah yang mengarah ke apikal; faktor mekanis yang didapat dari friksi yang terjadi pada daerah yang berkontak antara bagian GTSL dengan gigi asli yang masih ada. Stabilisasi didapat dari adaptasi landasan, pembebasan pada daerah frenulum, penyusunan gigi di atas 
linggir, penyusunan anasir memenuhi prinsip oklusi berimbang, penyusunan anasir membentuk kurva spee dan manson, mengunyah pada kedua sisi. Estetik didapatkan dari pemilihan bentuk, warna, dan ukuran gigi anasir yang tepat, serta kontur gigi.

\section{Tahapan penatalaksanaan kasus:}

- Kunjungan I

1. Pencetakan model studi untuk diskusi kasus.

- Pencetakan dilakukan dengan menggunakan bahan cetak hidrokoloid irreversible/ alginate menggunakan stock tray.

- Hasil cetakan negatif dicor menggunakan gips stone tipe II untuk mendapatkan cetakan positif.

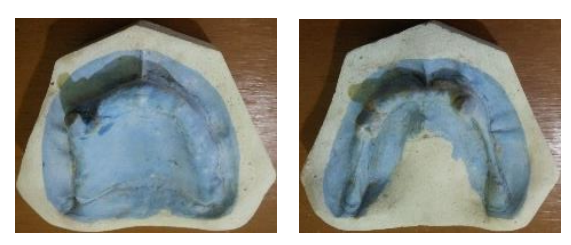

Gambar 4. Foto Model Studi

- Cetakan mencetak semua batas anatomi RA dan RB. Batas anatomi rahang atas: gigi geligi, frenulum labialis, frenulum bukalis, vestibulum labialis, vestibulum bukalis, papila insisivum, rugae palatine, fovea paltine, hamular notch, tuberositas maksila dan palatum. Batas anatomi rahang bawah : gigi geligi, frenulum labialis, frenulum bukalis, vestibulum labialis, vestibulum bukalis, retromolar pad dan mylohyoid ridge.

- Melakukan trimming pada model studi positif dan ditanam dalam basis segi tujuh.

2. Lab.

- Pembuatan sendok cetak perseorangan (SCP) dengan menggunakan bahan self cure resin akrilik.

- Yang harus diperhatikan pada sendok cetak individual: rahang atas seperti batas hamular notch, batas mukosa bergerak dan tidak bergerak dan batas mukogingival junction sedangakan pada rahang bawah seperti batas retromolar pad, batas sulkus alveoli lingual, batas mukogingival junction dan batas mukosa bergerak dan tidak bergerak (forniks).

- Tahapan kerja:

Pembuatan desain outline sendok cetak individual Outline mencakup semua gigi dan jaringan pendukung gigi tiruan, membuat garis pada forniks dengan pensil biru 
dan membuat garis dengan pensil merah $2 \mathrm{~mm}$ di atas garis biru (forniks) dan daerah frenulum dibebaskan.

$\checkmark$ Pembuatan wax spacer

Mengolesi permukaan model studi dengan vaselin. Melapisi model dengan selapis malam/ wax $(2 \mathrm{~mm})$ menutupi daerah tak bergigi sampai batas yang ditandai dengan pensil merah, sebagai ruangan untuk bahan cetak.

Pembuatan stopper

Membuat stopper 3 buah berbentuk segi empat dengan ukuran 4 × $2 \mathrm{~mm}$ dengan memotong wax spacer, satu pada anterior dan dua pada posterior kiri dan kanan.

$\checkmark$ Pemanipulasian akrilik swapolimerisasi

Mencampurkan powder dan liquid sesuai petunjuk pabrik, membuat akrilik dalam bentuk lempengan dan mengadaptasikan ke model yang ditutupi spacer dengan ketebalan akrilik 2 $\mathrm{mm}$.

$\checkmark$ Finishing sendok cetak individual
Membuang wax spacer, sendok cetak dirapikan, tidak ada bagian yang tajam dan membuat lubang-lubang (escape holes) pada sendok cetak untuk retensi menggunakan bur diamond, jarak tiap lubang $4,5 \mathrm{~mm}$.

- Kunjungan II

Perawatan pra prostodontik:

- Perawatan perio: scaling \& root planing.

- Perawatan bedah mulut: pencabutan gigi 13-22, 24-28, 33 42.

- Perawatan konservasi: restorasi resin komposit pada gigi 14 (klas II), 34 (klas II), 43 (klas III).

- Kunjungan III

Pembuatan sendok cetak fisiologis dan muscle trimming pada rahang atas dan bawah:

- Melakukan pengecekan tepian sendok cetak, apakah sudah mencakup semua daerah dan pas pada posisi anatomi rahang; tidak kurang dan tidak berlebih.

- Terdapat jarak antara sendok cetak dengan batas mukosa bergerak dan yang tidak bergerak sebagai tempat untuk manipulasi greenstick compound. 
- Setelah sendok cetak selesai, dilakukan muscle trimming. Caranya dengan memanaskan greenstick compound dan diletakkan pada bagian tepi sendok cetak.

- Kemudian dimasukkan kedalam mulut pasien. Bagian pipi, lidah, dan mukosa bergerak lainnya digerak-gerakkan atau dipijat sesuai gerakan fisiologis seperti mengerutkan bibir, menghisap, tersenyum, menggerakan dan menjulurkan lidah, megucapkan kata "Ah".

- Kunjungan IV

Pencetakan fisiologis:

- Pencetakan dilakukan dengan menggunakan bahan cetak elastomer pada rahang atas dan rahang bawah.

Lab:

- Pengecoran hasil cetakan negatif model kerja dengan menggunakan gips stone tipe III.

- Melakukan surveying pada model kerja untuk menentukan undercut untuk retensi.

- Melakukan blocking out pada daerah undercut yang tidak menguntungkan.

- Pembuatan basis dan bite rim gigi tiruan.
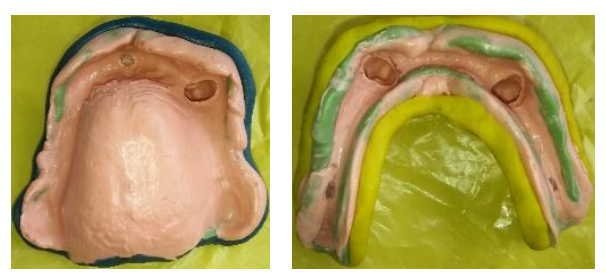

Gambar 5. Foto Cetakan

- Kunjungan V

1. Try in basis dan bite rim gigi tiruan RA dan RB.

2. Penentuan kesejajaran bite rim RA dengan menggunakan alat bantu bite fox, benang jagung yang diletakkan pada garis yang melalui tragus dan ala nasi.

3. Penentuan relasi sentrik (RS) dan dimensi vertikal (DV).

Penentuan dimensi vertikal dilakukan dengan cara:

- Pasien diposisikan dalam keadan rileks dan tragus dan alanasi sejajar lantai.

- Beri tanda berupa dua titik pada wajah yaitu pada puncak hidung dan paling menonjol pada dagu pasien.

- Pasien diinstruksikan untuk menelan dan rahang bawah dibiarkan dalam keadaan posisi istirahat fisiologis, ukur jarak kedua titik.

- Kemudian pasien diinstruksikan untuk mengucapkan huruf 'mmm' dan secara bersamaan dilakukan pengukuran jarak kedua titik tersebut. Apabila 
hasil dari kedua pengukuran sama, maka posisi tadi dapat diterima sebagai dimensi vertikal istirahat. Pengukuran ini dilakukan beberapa kali, pasien diajak berbicara dan rileks di antara kedua pengukuran tersebut.

- Setelah ukuran dimensi vertikal istirahat diperoleh, kemudian dikurangi dengan jarak free way space sekitar 2-3 $\mathrm{mm}$ sehingga didapatkan hasil akhir yang merupakan dimensi vertikal oklusal tentative.

- Masukkan bite rim rahang atas, lunakkan bagian bite rim yang sekiranya berkontak dengan gigi asli. Instruksikan pasien untuk mengulangi hal seperti di atas, sehingga didapatkan posisi dan hasil pengukuran DVO yang sama dengan sebelumnya.

- Biterim RA tetap ada dalam mulut dan masukkan biterim $\mathrm{RB}$, lunakan bagian bite rim yang sekiranya berkontak dengan gigi asli. Instruksikan pasien untuk mengulangi hal seperti di atas, sehingga didapatkan posisi dan hasil pengukuran DVO yang sama dengan sebelumnya.
- Masukan bite rim RA dan RB, instruksikan kembali, dan dikatakan selesai apabila hasil pengukuran DVO tetap sama.

4. Fiksasi bite rim RA dan RB dengan hecter, pastikan bite rim sudah dalam keadaan kontak bidang.

5. Lab: penanaman model kerja + bite rim yang sudah difiksasi di artikulator.

Cara pemasangan model pada artikulator:

- Mengolesi kedua lengan artikulator yang akan diberi gips dengan vaseline.

- Memasang karet gelang pada pertengahan artikulator.

- Model dan oklusal rim yang telah difiksasi diletakkan pada artikulator dengan meletakkannya menggunakan plastisin pda lengan bawah artikulator.

- Posisi model dan oklusal rim tepat dengan pedoman:

$\checkmark$ Lengan horizontal atas dan bawah sejajar lantai.

$\checkmark$ Pin vetikal terpasang tepat pada lekukan tengah dan ujung pin berkontak dengan meja insisal artikulator di bawahnya.

$\checkmark$ Pin horizontal harus dipasang tepat pada 
lekukannya dan ujung pin tepat berada pada perpotongan garis median oklusal rim dengan bidang oklusal anterior.

$\checkmark$ Dataran oklusal rim sejajar atau berhimpit dengan karet gelang yang dipasang pada artikulator (dilihat dari arah lateral).

$\checkmark$ Garis median model berhimpit dengan garis median artikulator (dilihat dari arah lengan atas artikulator).

- Lengan atas artikulator dan model rahang atas dilekatkan dengan gips putih.

- Setelah mengeras, artikulator dibalik dan plastisin dilepas kemudian lekatkan dengan gips putih pada model rahang bawah dengan lengan bawah artikulator.

- Setelah gips mengeras dan dingin, karet gelang dan fiksasi oklusal rim dilepaskan.
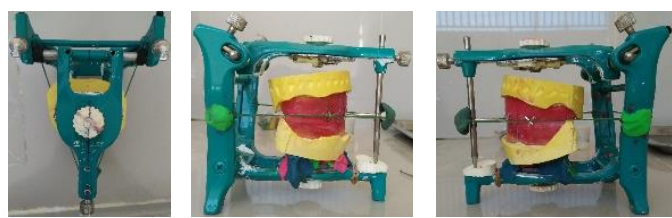

Gambar 6. Foto persiapan artikulator

- Kunjungan VI

1. Lab: penyusunan anasir gigi tiruan rahang atas dan bawah.
Penyusunan dilakukan dimulai dari anterior rahang atas-bawah, posterior kanan atas-bawah dan posterior kiri atas-bawah.

2. Try in gigi tiruan malam

Penilaian terhadap semua aspek:

- Perluasan sayap, adaptasi, retensi dan stabilisasi

$\checkmark$ Menginstruksikan pasien untuk melakukan gerakan fungsional dari bibir dan pipi.

$\checkmark$ RA : memeriksa distobukal dari hamular notch dan daerah vibrating line.

$\checkmark$ RB : memeriksa posisi occlusal plane anasir sedikit di atas tepi lateral lidah.

$\checkmark$ Basis tidak terangkat saat pengecekan.

- Pemeriksaan estetik, penilaian:

$\checkmark$ Buccal support.

$\checkmark$ Permukaan oklusal gigi posterior RA sejajar dengan garis chamfer.

$\checkmark$ Tinggi bidang oklusal RB setinggi $2 / 3$ retromolar pad.

Warna, bentuk dan ukuran anasir sesuai dengan wajah dan gigi asli yang tersisa.

- Pemeriksaan dimensi vertikal: 
Pengukuran: menentukan titik subnasion dan gnation, instruksikan pasien rileks, mengukur 2 titik didapat DVI. Memasukkan RA dan RB, mengukur DVO, harus sama dengan DVO saat penentuan DVO awal.

- Pemeriksaan relasi sentrik.

- Pemeriksaan oklusi: Mengintruksikan pasien untuk oklusi sentrik dengan memeriksa dengan kaca mulut dan tidak boleh ada open bite.
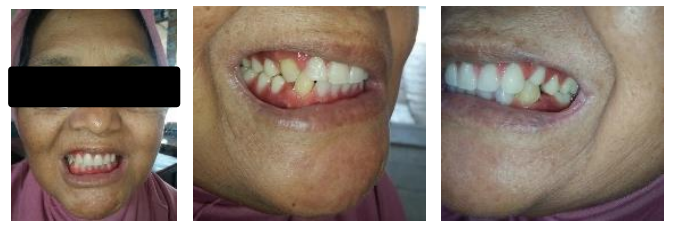

Gambar 7. Foto try in malam

3. Lab: modelir malam (27-012020), flasking, curing, finishing, dan polishing.

Modelir malam, tahap:

$\checkmark$ Memanaskan dan meletekkan malam setebal kira-kira $2 \mathrm{~mm}$ dan dilakukan pada seluruh permukaan secara merata.

$\checkmark$ Pada permukan bukal posterior rahang atas dibuat cembung sampai menutupi tuberositas.

$\checkmark$ Daerah marginal gingiva dibuat cekung.

$\checkmark$ Bagian posterior sayap bukal berbentuk semisirkuler.
Daerah servikal dibentuk sebatas daerah garis servikal dan anasir gigi tiruan menyerupai jaringan pendukung gigi asli, bentuk akar yang tertanam dalam tulang rahang/ root prominensia.

$\checkmark$ Daerah interproksimal sedikit cembung untuk meniru bentuk interdental papila.

$\checkmark$ Permukaan gigi tiruan malam dihaluskan dengan kapas alkohol sampai mengkilat.

- Kunjungan VII

1. Insersi gigi tiruan.

- Evaluasi gigi tiruan: tidak ada porus, mengkilat, halus, tidak tajam, tidak ada gips.

- Rongga mulut sehat, tidak ada eritema/ ulserasi.

- Pada kunjungan pertama saat prosedur insersi gigi tiruan rahang atas dan bawah, gigi tiruan tidak dapat langsung masuk secara sempurna, karena adanya sangkutan pada bagian gasketnya. Kemudian, dilakukan pengurangan sedikit demi sedikit secara hati-hati untuk menghilangkan sangkutan dengan menggunakan bur akrilik. Pada kunjungan kedua, gigi tiruan 
rahang atas dan rahang bawah sudah dapat masuk.

- Pada kunjungan kedua ini dilanjutkan dengan penyelarasan oklusal.

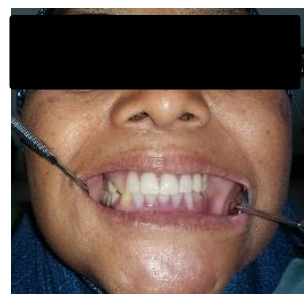

Gambar 8. Foto insersi (penyelarasan oklusal)

\section{DISKUSI}

Pasien yang memiliki sedikit gigi tersisa dapat dirawat dengan pembuatan over denture atau immediate denture atau transitional denture. Over denture tidak selalu menjadi perawatan yang paling tepat untuk semua kasus akibat adanya kontraindikasi, kebutuhan perawatan endodontik, kebutuhan pasien untuk kunjungan yang lebih banyak dan alasan finansial. ${ }^{3}$ Perawatan pada pasien dilakukan dengan pembuatan gigi tiruan sebagian lepasan dengan disain gasket pada gigi yang tersisa. Perawatan ini dipilih karena pada rahang atas pasien hanya satu gigi yang tersisa, yaitu gigi 14 dan pada rahang bawah pasien hanya dua gigi yang tersisa, yaitu gigi 34 dan 43. Gigi dipilih untuk dipertahankan dengan alasan agar gigi asli tetap berada dalam rongga mulut pasien selama mungkin; selain itu pasien juga menginginkan gigi aslinya sebisa mungkin untuk tidak dicabut. Banyak pasien menginginkan untuk menunda giginya diekstraksi karena alasan psikologi. Oleh karena itu, $C u$ sil denture dapat menjadi pilihan perawatan. $^{3}$

$\mathrm{Cu}$-sil denture bertujuan untuk menjaga seluruh gigi asli yang tersisa dan memiliki efek positif terhadap retensi dan stabilisasi pada gigi tiruan. Gigi tiruan ini memberikan kepuasan psikologi terhadap pasien dalam menjaga gigi aslinya. Tidak ada teknik pencetakan dan bahan khusus yang dibutuhkan. Relining pada masa akan datang dapat dilakukan. $\mathrm{Cu}$ sil denture dapat dijadikan full denture jika nantinya pasien mengalami kehilangan gigi aslinya. $\mathrm{Cu}$ sil denture ini menjadi suatu solusi pada pasien yang memiliki sedikit gigi asli yang tersisa. ${ }^{3}$ Dimensi vertikal dan efek proprioseptif dapat dijaga ketika kita mempertahankan gigi asli. Perawatan ini tidak membutuhkan preparasi gigi dan kunjungan ekstra pada pasien. ${ }^{4}$

Magnet telah popular dalam kedokteran gigi karena magnet menjadi resisten terhadap korosi dan dapat meningkatkan restensi GT. Indikasinya pada gigi asli yang tersisa sedikit dimana overdenture dapat digunakan. Hal ini dapat menjadi suatu preservasi pada akar sehingga dapat menjaga prosesus alveolar dari resorbsi tinggi wajah dapat dipertahankan. 


\section{SIMPULAN}

$\mathrm{Cu}$-sil denture pada dasarnya merupakan gigi tiruan lengkap dengan lubang yang membuat gigi asli yang tersisa dapat muncul pada gigi tiruan. Lubang tersebut dikelilingi oleh gasket yang memeluk leher dari gigi asli, sehingga terbentuk suatu natural suction pada gigi tiruan. Gigi tiruan dengan gasket ini dapat dijadikan salah satu pilihan perawatan pada kasus dengan sedikit gigi asli tersisa. Gigi asli dapat dipertahankan sehingga dapat menjaga integritas alveolar ridge dan efek proprioseptif. Apabila nantinya ditemui keadaan dimana gigi asli tersebut tidak dapat dipertahankan lagi, gigi tiruan gasket ini dapat dimodifikasi untuk dijadikan gigi tiruan lengkap.

\section{KEPUSTAKAAN}

1. Pereira et al. Literature review: partially denture arches main classifications. Jacobs Journal of Dentistry and Research. 2014; 1(2): 11.

2. Campbell et al. Removable partial dentures: the clinical need for innovation. The Journal of Prosthetic Dentistry. 2017; 118: 273-280.

3. Jayesh et al. $\mathrm{Cu}$-sil dentures - a novel approach to conserve few remaining teeth: case reports.
Journal of International Oral

Health. 2015; 7(8): 138-140.

4. Jain, Aishish R. Cu-sil denture for patients with few remaining teeth a case report. Journal of Advanced Pharmacy Education and Research. 2017; 7(3): 332-334.

5. Manohar et al. Management of a case with few remaining teeth with a splinted coping magnet retained overdenture. Journal of Applied Dental and Medical Sciences. 2016; 2(1): 38-43. 